\title{
PENGARUH KEAUSAN RING PISTON TERHADAP KINERJA MESIN
}

\author{
DiditSumardiyanto, Syahrial Anwar \\ FakultasTeknikJurusanTeknikMesin \\ Universitas 17 Agustus 1945 Jakarta
}

\begin{abstract}
Abstrak
Penelitianinidilakukanuntukmengetahuipengaruhkeausan ring piston padamesin diesel $B \& W$ Type : 6S50MC, terhadapkinerjamesin.Penelitian dilakukan dengan mencatat data-data indicator kinerja mesin sebelum dilakukan penggantian dan setelah dilakukan penggantian ring piston.Hasil yang diperoleh Pada kondisi ring piston belum dilakukan penggantian Daya Efektif sebesar $11.959 \mathrm{hp}$. Efisiensi thermal Efektif 36.96\% dan Konsumsi Bahan Bakar Spesifik sebesar $171 \mathrm{~g} / \mathrm{hp} . \mathrm{h}$, Sedangkan pada kondisi ring piston sesuai dengan standar, mesin menunjukkan kinerja, Daya Efektif 12.899 hp, Efisiensi Thermal Efektif 39.8\%, dan konsumsi bahan bakar spesifik sebesar $158.8 \mathrm{~g} / \mathrm{hp} . \mathrm{h}$
\end{abstract}

Kata Kunci :

Mesin diesel, ring piston, kinerja mesin

\section{PENDAHULUAN}

Prinsip utama proses pembakaran pada mesin diesel adalah mengkompresi udara pembakaran yang "terjebak" di dalam ruang bakar sehingga tekanan dan temperaturnya melampaui titik nyala secara spontan bahan bakar mesin diesel. Sehingga tekanan pada akhir kompresi menentukan besarnya tekanan akhir pembakaran. Oleh karena itu pada saat proses kompresi dihindari semaksimal mungkin terjadinya kebocoran yang akan berpengaruh pada tekanan kompresi.

Akibat pengoperasian mesin yang tidak memenuhi standar, maka ring piston akan mengalami keausan lebih awal. Kondisi yang berpengaruh terhadap kecepatan keausan ring piston diantaranya adalah : terlalu awal mesin dibebani dan proses pembakaran yang tidak sempurna sehingga terjadi arang karbon disela-sela ring piston.

Akibat dari kondisi tersebut adalah menurunkan kinerja mesin dan pada akhirnya menyebabkan pemborosan.

\section{TUJUAN PENELITIAN}

Tujuan penelitian adalah untuk mengetahui pengaruh keausan ring piston terhadap kinerja mesin diesel

\section{TINJAUAN PUSTAKA}

Mesin diesel adalahsalahsatumesinkonversienergipembakarandalamjenistorak, yang mengubahenergitermalhasilreaksikimiaantarabahanbakardanudara, menjadienergimekanis.Pada mesin diesel proses penyalaan bahan bakar terjadi secara spontan akibat temperature campuran antara udara dan bahan bakar melampaui pembakaran spontan dari bahan bakar. Pada Gambar1 ditunjukkan temperatur akhir kompresi mencapai lebih $400{ }^{\circ} \mathrm{C}$, sedangkan penyalaan spontan bahan bakar terjadi di bawah temperatur $400{ }^{\circ} \mathrm{C}$. Besarnya daya yang dihasilkan oleh mesin 
diesel tergantung pada banyaknya bahan bakar yang dapat terbakar dengan sempurna di dalam ruang bakar. Tekanan yang terjadi akibat proses pembakaran tergantung pada tekanan akhir kompresi udara oleh piston. Jika terjadi kebocoran pada saat mengkompresi udara pembakaran, maka menyebabkan tidak maksimalnya tekanan akhir pembakaran. Akibatnya gaya dorong yang diterima oleh piston menjadi berkurang.

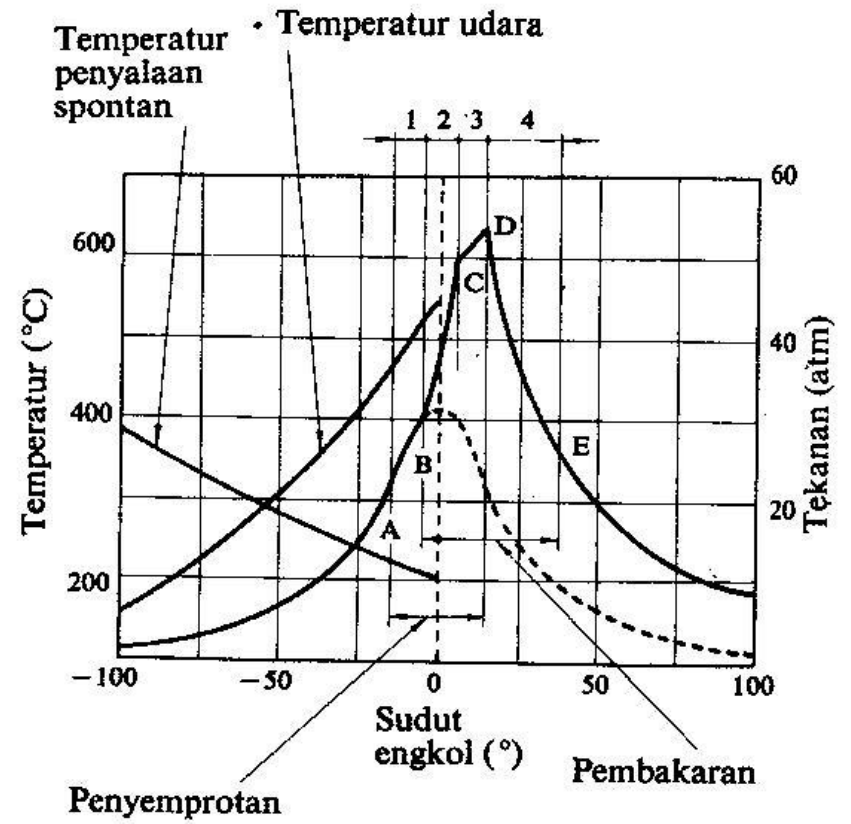

\section{Gambar 1 Diagram indikator hipotektik mesin diesel ${ }^{1}$}

Hal tersebut disebabkan karena perbandingan kompresi pada mesin diesel yang tinggi, yaitu berkisar antara 1:12 sampai dengan 1: 20, sehingga pada saat menjelang akhir kompresi bahan bakar dimasukkan/diinjeksikan ke dalam ruang bakar dalam bentuk kabut halus, sesaat kemudian bahan bakar secara spontan akan terbakar dengan sendirinya, oleh karenanya disebut juga compression ignition engine (CIE).Secara teoritis siklus kerja mesin diesel seperti terlihat pada Gambar 2 Pemasukan kalor (proses pembakaran) terjadi pada tekanan konstan. 

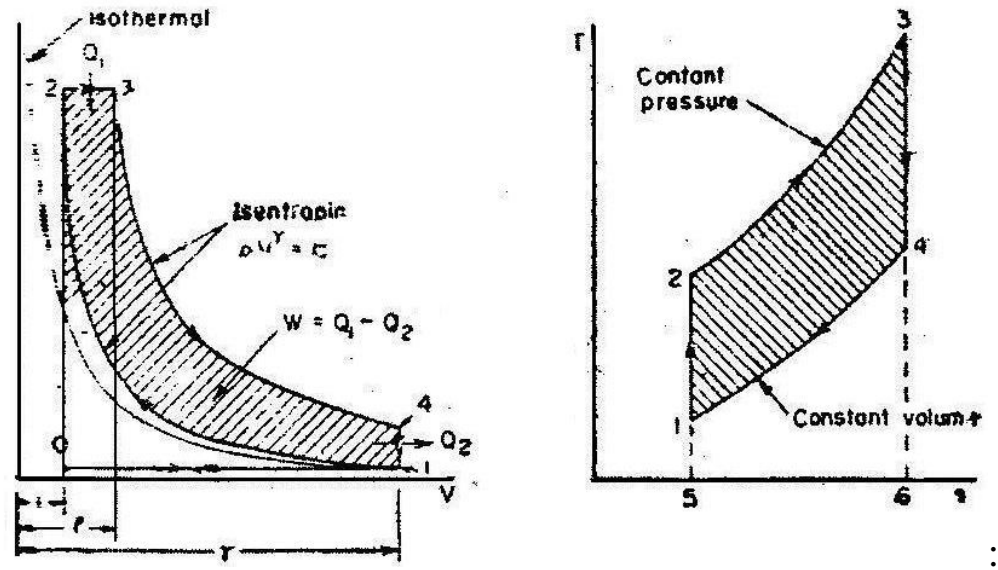

Gambar 2 Diagram P-V dan T-S pada siklus kerja mesin diesel

Keterangan :

Proses 1-2 : Kompresi Isentropis (reversibel adiabatis)

Proses 2-3 : Proses Pembakaran pada Tekanan Konstan (Isobaric)

Proses 3-4 : Ekspansi Isentropis

Proses 4-1 : Pelepasan kalor pada volume konstan (Isokhoric)

$\mathrm{Q}_{1} \quad$ : Energi termal yang dimasukkan ke sistem

$\mathrm{Q}_{2} \quad$ : Pelepasan gas sisa pembakaran

W : Kerja yang dihasilkan oleh sistem

Ditinjau dari siklus/daur pembakarannya, mesin diesel dibedakan menjadi 2 golongan, yaitu :

- Diesel 2 Langkah atau 2 Tak,

Pada mesin diesel 2 Tak, untuk melakukan 1 siklus kerja diperlukan 1 putaran poros engkol (crankshaft) atau 2 kali langkah piston, yaitu satu kali langkah maju dan satu kali langkah mundur.

- Diesel 4 Langkah

Pada mesin diesel 4 Tak, 1 siklus pembakaran ditempuh melalui 2 putaran poros engkol atau 4 langkah piston

\section{Elemen-elemen Penghasil Daya}

Elemen-elemen yang berkaitan dengan penghasil daya, diantaranya adalah :

1. Piston beserta ring piston, piston pin dan bushing

2. Lengan ayun (connecting rods)

3. Poros engol Icrank shaft)

4. Silinder

5. Katup isap/buang

6. Cilynder head

\section{Ring Piston}

Fungsi ring piston adalah untuk merapatkan celah antara piston dan silinder liner agar tidak terjadi kebocoran saat proses kompresi.Oleh karenanya kondisi ring piston sangat berpengaruh terhadap hasil akhir kompresi di dalam silinder dari sebuah mesin. 

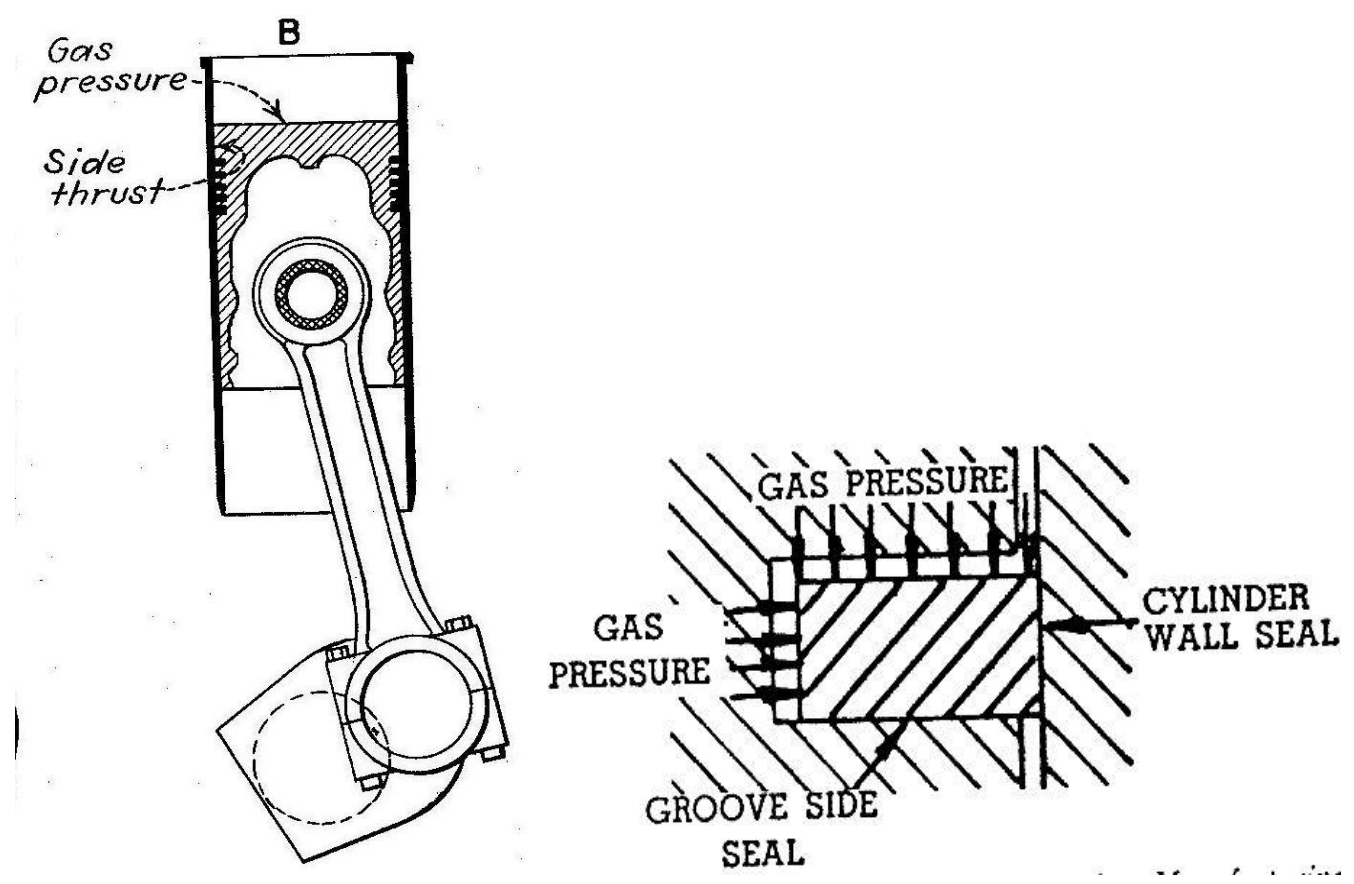

Gambar 3 Tekanan gas pembakaran terhadap ring kompresi

Pada Gambar 2.3 ditunjukkan tekanan yang diterima oleh permukaan piston, yaitu berupa gesekan terhadap dinding silinder, berupa dorongan akibat tekanan dari ruang bakar dan dari dinding silinder.

Untuk mengurangi kecepatan-ausan dari ring piston akibat gesekan, maka antara ring piston dan silinder diberi pelumasan yang cukup..

Beberapa penyebab kerusakan pada ring piston diantaranya adalah :

- Terlalu kencang (pressure gap terlalu sempit)

- Terjadi masalah pada sistem pelumasan silinder

- Deposit carbon akibat pembakaran yang tidak sempurna atau pengotor lainnya

- Mesin dioperasikan pada saat belum cukup panas

\section{Dasar Perhitungan Kinerja Mesin}

DayaEfektifatauDaya Poros (Ne)

DayaefektifataudisebutdengannamaDaya Poros, adalahdayariil yang dihasilkanolehmesin yang bisa dimanfaatkansebagaitenagapenggeerak, baikuntukpenggerak alternador (pada mesin diesel generador) maupununtuksumberpenggerak poros alattransportasi (penggerakpropeler pada papal atausebagaipenggerak as roda pada kendaraandarat).

Dayaefektifadalahdaya yang dihitung/diukurberdasarkanbesarnyaTorsi pada poros engkoldikalikandengankecepatanputarnya.

UntukmengetahuibesarnyatorsidipergunakanDinamometer.

$$
N e=\frac{T \cdot n}{716.19}(h p)
$$

Dimana :

$N_{e}$ : Daya Efektif (hp)

$T$ : Torsi (N.m)

$n:$ Kecepatan putar poros engkol (rpm) 


\section{Efisiensi Thermal Efektif}

\section{Dimana :}

$G_{b b}$ : Jumlah bahan bakar yang dikonsumsi (kg/jam)

$N_{e}$ : Daya Efektif (hp)

$H_{b}$ :Nilai kalor bahan bakar, rata-rata $: 10.000 \mathrm{kcal} / \mathrm{kg}$.

\section{Konsumsi Bahan Bakar Spesifik}

Konsumsi bahan bakar spesifik adalah jumlah (kg) bahan bakar yang diperlukan untuk menghasilkan Daya sebesar $1 \mathrm{hp}$ dalam waktu satu jam. Semakin besar nilai Konsumsi Bahan Bakar Spesifik dari pengoperasian sebuah mesin, maka artinya mesin tersebut semakin boros. Titik optimal dari suatu mesin adalah kondisi dimana kebutuhan bahan bakar untuk menghasilkan daya adalah yang paling kecil.

Besarnya konsumsi bahan bakar spesifik dari suatu mesin dapat diperoleh dari persamaan berikut ${ }^{2}$ :

$$
b_{e}=\frac{632}{H_{b} x \eta_{t e}}(\mathrm{~kg} / \mathrm{hp} . \mathrm{h})
$$

Dimana :

$H_{b}$ : Nilai kalor bahan bakar $(\mathrm{kcal} / \mathrm{kg})$

$\eta_{t e}$ : Efisiensi thermal efektif (\%)

\section{METODE PENELITIAN}

Penelitian ini dilakukan melalui beberapa tahapan. Adapun urutan tahapan yang dilakukan adalah seperti terlihat pada Gambar 4 


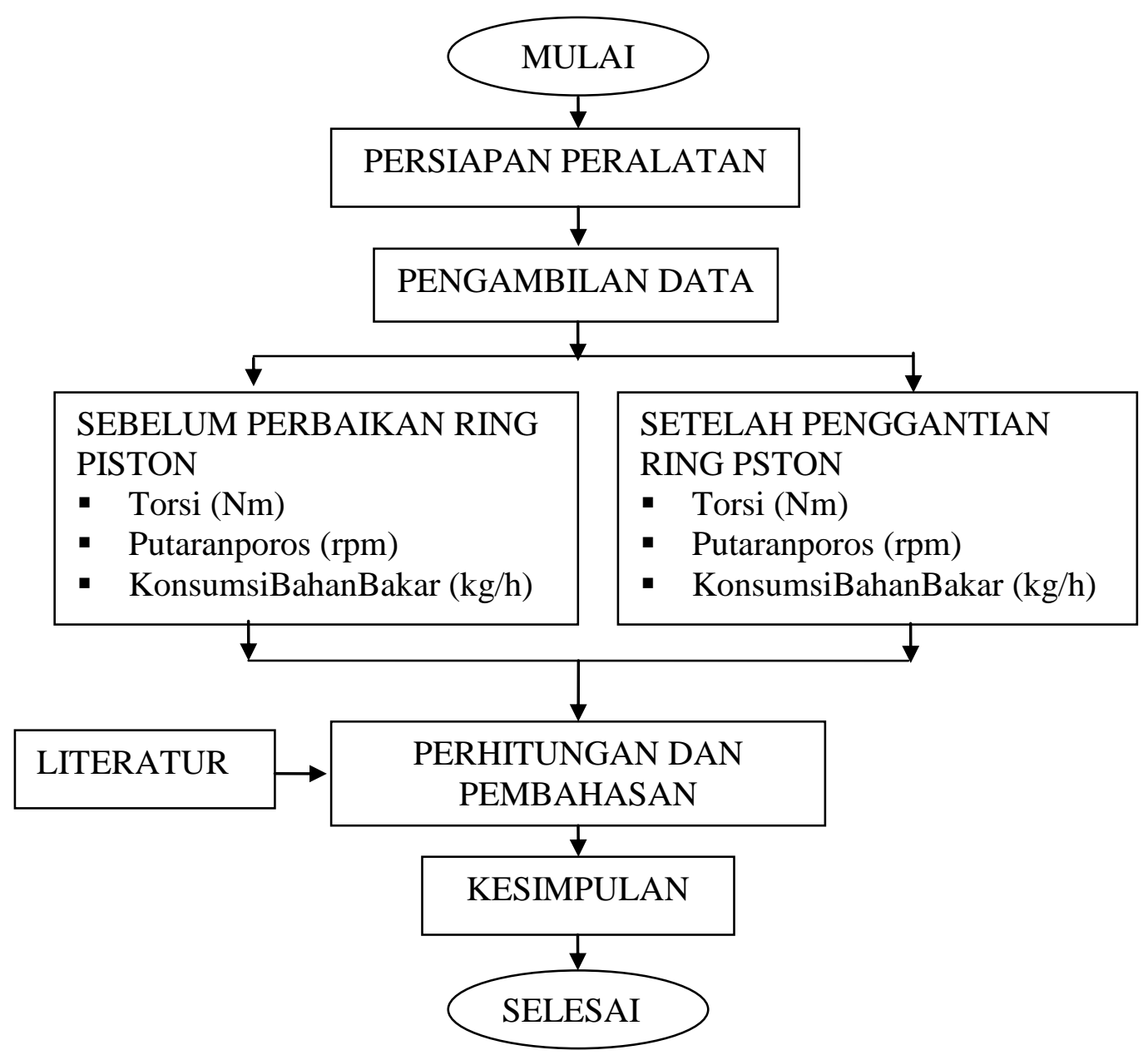

Gambar 4 Diagram Alir Penelitian

\section{DATA DAN PEMBAHASAN}

\section{Data Hasil Penelitian}

Spesifikasi Teknis

$$
\begin{array}{lll}
\text { - } & \text { Merek } & : \text { B\&W, 6S50MC, } 2 \text { stroke engine } \\
\text { - } & \text { Panjaneter silinder } & : 500 \mathrm{~mm} \\
\text { - } & \text { Power output } & : 2000 \mathrm{~mm} \\
\text { - Putaran } & : 127 \mathrm{rpm} \\
\text { - Jumlah silinder } & : 60
\end{array}
$$

\section{Data Hasil Pengukuran}

Kondisi celah ring piston sebelum penggantian dan setelah penggantian 


\section{Celah Ring Piston Pada Saat Mengalami Keausan}
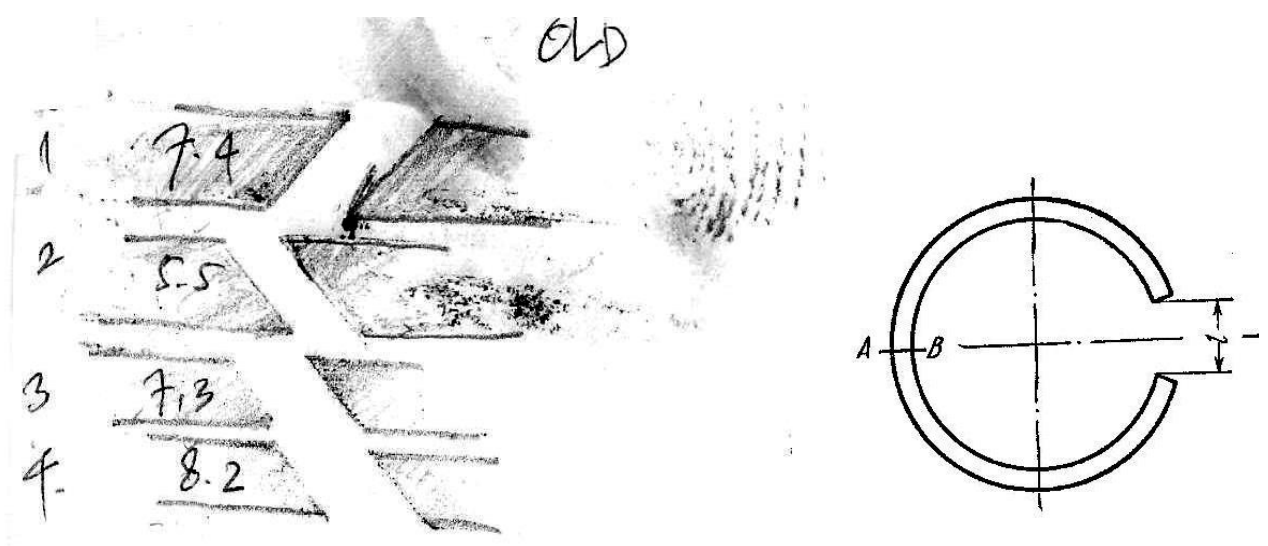

Gambar 5. Kondisi celah ring piston sebelum perbaikan

\section{Celah Ring Piston Setelah Penggantian}

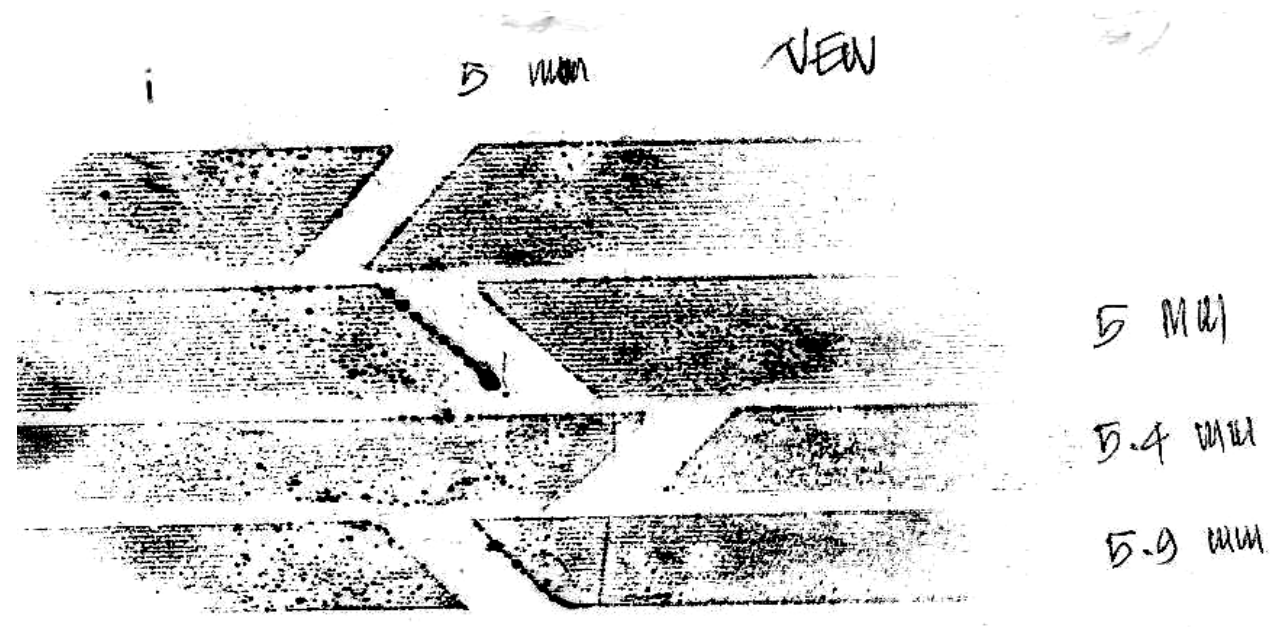

Gambar 6. Kondisi celah piston sesudah diadakan penggantian 
Tabel 1 Data hasil pengukuran

\begin{tabular}{|l|c|c|}
\hline \multirow{2}{*}{\multicolumn{1}{|c|}{ INDIKATOR }} & \multicolumn{2}{|c|}{ KONDISI RING PISTON } \\
\cline { 2 - 3 } & $\begin{array}{c}\text { SEBELUM } \\
\text { PERBAIKAN }\end{array}$ & $\begin{array}{c}\text { SETELAH } \\
\text { PENGGANTIAN }\end{array}$ \\
\hline Putaran, rpm & 127 & 127 \\
\hline Konsumsi B. Bakar, kg/jam & 2045 & 2045 \\
\hline Torsi, kg.m & 6882 & 7423 \\
\hline Kondisi Gas Buang & Lebihtebal & Normal \\
\hline
\end{tabular}

Catatan : Data ini diambil berdasarkan putaran mesin dan konsumsi bahan bakar yang sama

\section{PerhitunganKinerja Mesin Pada Kondisi Ring Piston mengalami Keausan}

\section{Daya Efektif (Ne)} daya efektif :

Yaitu daya yang riil yang bisa dihasilkan oleh mesin melalui poros engkol, besarnya

$$
N e=\frac{T \cdot n}{716,2}(h p)
$$

dimana :

$T: 6882 \mathrm{~kg} \cdot \mathrm{m}=67443.6 \mathrm{~N} \cdot \mathrm{m}\left(\mathrm{g}=9.8 \mathrm{~m} / \mathrm{s}^{2}\right)$

$n:$ Kecepatanputar poros, $127 \mathrm{rpm}$

MakaDayaEfektif :

$$
N e=\frac{67443.6 \times 127}{716.2}=11959(h p)
$$

\section{Efisiensi Termal Efektif}

Yaitu suatu nilai yang menunjukkan kemampuan mesin (menghasilkan daya efektif) terhadap kalor yang dibangkitkan di dalam silinder

$$
\eta_{t e}=\frac{N_{e} x 632}{G_{b b} x H_{b}}
$$

Dimana :

$G_{b b}:$ Jumlah bahan bakar yang dikonsumsi $=2045(\mathrm{~kg} / \mathrm{jam})$

$N_{e}:$ Daya Efektif $=11959(h p)$

$H_{b}$ : Nilai kalor bahan bakar : $10.000 \mathrm{kcal} / \mathrm{kg}$

Maka efisiensi termal efektif :

$$
\eta_{t e}=\frac{11959 \times 632}{2045 \times 10000} \times 100 \%=36.96 \%
$$

\section{Konsumsi Bahan Bakar Spesifik}

$$
b_{e}=\frac{632}{H_{b} x \eta_{t e}}(\mathrm{~kg} / \mathrm{hp} . j \mathrm{jam} .)
$$


Dimana $:=9600(\mathrm{kcal} / \mathrm{kg})$

$\eta_{\text {te }}:$ Efisiensithermal

$\mathrm{H}_{\mathrm{b}}$ : Nilai kalor bahan bakar efektif $=36.96(\%)$

$$
b_{e}=\frac{632}{9600 \times 36.96 \%}=0,178(\mathrm{~kg} / \mathrm{hp} . j \mathrm{jam} .)=178(\mathrm{~g} / \mathrm{hp} . \mathrm{h})
$$

\section{Kinerja Mesin Pada Kondisi Ring Piston Sudah Diganti Daya Efektif (Ne)}

Yaitu daya yang riil bisa dihasilkan oleh mesin melalui poros engkol, besarnya daya efektif :

$$
N e=\frac{T \cdot n}{716,2}(h p)
$$

Dimana :

$T: 7,423 \mathrm{~kg} \cdot \mathrm{m}=72745.4 \mathrm{~N} . \mathrm{m}\left(\mathrm{g}=9.8 \mathrm{~m} / \mathrm{s}^{2}\right)$

$n$ : Kecepatanputarporos, $127 \mathrm{rpm}$

MakaDayaEfektif :

$$
N e=\frac{72745.4 \times 127}{716.2}=12.899(\mathrm{hp})
$$

\section{Efisiensi Termal Efektif}

$\eta_{t e}=\frac{N_{e} x 632}{G_{b b} x H_{b}}$

dimana :

$G_{b b}$ : Jumlah bahan bakar yang dikonsumsi $=2045(\mathrm{~kg} / \mathrm{jam})$

$N_{e}:$ Daya Efektif $=12899(h p)$

$H_{b}$ : Nilai kalor bahan bakar : $9.600 \mathrm{kcal} / \mathrm{kg}$.(dari spesifikasi bahan bakar)

Maka efisiensi termal efektif :

$$
\eta_{t e}=\frac{12899 \times 632}{2045 \times 9600} \times 100 \%=41.5 \%
$$

\section{Konsumsi Bahan Bakar Spesifik}

$$
b_{e}=\frac{632}{H_{b} x \eta_{t e}}(\mathrm{~kg} / \mathrm{hp} . \mathrm{jam} .)
$$

Dimana :

$\mathrm{H}_{\mathrm{b}}$ : Nilai kalor bahan bakar $=9600(\mathrm{kcal} / \mathrm{kg})$

$\eta_{\text {te }}:$ Efisiensithermalefektif $=41.5(\%)$

$b_{e}=\frac{632}{9600 \times 41.5 \%}=0,1586(\mathrm{~kg} / \mathrm{hp} . \mathrm{jam})=.158.6(\mathrm{~g} / \mathrm{hp} . \mathrm{h})$ 
Tabel2. HasilPerhitungan

\begin{tabular}{|l|c|c|c|c|}
\hline & & \multicolumn{2}{|c|}{ KONDISI RING PISTON } & PERBEDAAN \\
\cline { 3 - 5 } INDIKATOR KINERJA & SATUAN & $\begin{array}{c}\text { Sebelum } \\
\text { Perbaikan }\end{array}$ & $\begin{array}{c}\text { Setelah } \\
\text { Diganti }\end{array}$ & $\%$ \\
\hline DayaEfektif, Ne & $\mathrm{hp}$ & 11959 & 12899 & 7.86 \\
\hline Eff.ThermalEfektif & $\%$ & 36.96 & 41.5 & 12.3 \\
\hline Kons. BB Spesifik, be & $\mathrm{g} / \mathrm{hp} . \mathrm{h}$ & 178 & 158.6 & 10.88 \\
\hline
\end{tabular}

\section{KESIMPULAN}

Darihasilpengecekan

di

lapangan, ring pistondaribeberapasilindertelahmengalamikeausan. dilihatdarilebarcelah ring piston.

Dari data-data tersebut, makasetelahdilakukanperhitungan, akibatterjadinyakeausan pada ring piston, kinerjamesinmenjadimenurun. Dayaefektifturundari $12.899 \mathrm{hp}$ menjadi $11.959 \mathrm{hp}$, atauturunsebesar 7.86\% Akibatmenurunnyadayaefektif, makamenyebabkanefisiensi termal efektif, yaitudari41.5\% menjadi 36,96\%, dan akibatnyakonsumsibahanbakarspesifiknaikdari $158.6 \mathrm{~g} / \mathrm{hp} . \mathrm{hmenjadi} \quad 178 \mathrm{~g} / \mathrm{hp}$. Artinyamesinlebih boros 10.88\%, setiapjamuntukmenghasilkandayaefektifsebesar $1 \mathrm{hp}$.

Pada gas buang, untukmesin pada kondisi ring piston yang mengalamikeausanmemilikiasap yang lebih tabal dibandingkandengan ring piston yang telahmendapatperbaikan, haltersebutdikarenakanpelumasdari ring pistonikutterbakar dan keluarbersama-sama gas buang.

\section{DAFTAR PUSTAKA}

1. Aris Munandar, Wiranto, penggerak Mula Motor Bakar Torak, ITB Edisi ke-4, Bandung, 1988.

2. J. P. Holman, Perpindahan Kalor, Erlangga, Jakarta, 1995

3. Ir. M. J. Djoko Satyardjo, Ketel Uap, Paramita Edisi ke-5, Jakarta, 2003 